\title{
Analisis Sistem Informasi Dalam Diteksi Eror Visual Perkuliahan Daring Dengan Metode Longitudinal Redundancy Check (LRC)
}

\author{
Sepryhatin Dioputra ${ }^{1}$, Novi Rukhviyanti ${ }^{2}$ \\ ${ }^{1,2}$ Program Studi Sistem Informasi \\ ${ }^{1,2}$ STMIK Indonesia Mandiri, Jl.Jakarta No.79 Bandung \\ Email : sepryhatindioputra@rocketmail.com ${ }^{1}$,novi.rukhviyanti@stmik-im.ac.id²
}

\begin{abstract}
ABSTRAK
Daring (Online) di era globalisasi revolusi industri 4.0 dalam bidang pendidikan sewajarnya menjadi suatu sarana yang harus lebih di perhatikan pemerintah dalam menunjang kegiatan belajar dan mengajar, terutama di dalam situasi darurat wabah covid-19, perkuliahan daring (online) merupakan sarana utama dalam pembelajaran yang harus di tempuh mahasiswa guna menyelesaiakan perkuliahan. Dalam penerapannya perkuliahan daring (online) seringkali mengalami banyak kendala yang salah satunya adalah gangguan atau eror visual disaat perkuliahan berlangsung.

Gangguan atau eror pada visual yang terjadi dapat di diteksi dengan banyak metode, salah satunya metode Longitudinal Redundancy Check (LRC) yang memberikan hasil analisis sistem, dengan transfer data yang di lakukan secara per blok. Didalam blok terdiri dari 8 byte dan setiap blok memiliki karakter pemeriksa blok yang ditempatkan pada akhir blok dengan metode sederhana sistem interaktif operator memasukan data melalui terminal juga mengirimkan ke komputer sehingga menampilkan kembali ke terminal, agar dapat memeriksa apakah data yang dikirimkan telah benar.
\end{abstract}

Kata Kunci : Analisis Sistem Informasi, Daring, Longitudinal Redundancy Check (LRC).

\section{ABSTRACT}

Daring in the era of globalization of the industrial revolution 4.0 in the field of education, it should be a means that the government should pay more attention to in supporting teaching and learning activities, especially in an outbreak emergency covid19 situation, online lectures is the main means of learning that students must take to complete lectures. often experience many obstacles, one of which is visual disturbances or errors during the lecture.

Error the visual that occurs can be detected by many methods. one of them Longitudinal Redundancy Check (LRC) method, which provides system analysis results, with data transfer done in a block manner Inside the block consists of 8 bytes and each block has a block check character that is placed at the end of the block with a simple method the operator's interactive system enters data through the terminal also sends it to the computer so that it displays it back to the terminal, in order to check whether the data sent is correct.

Keyword : Analysis Information Systems, Online, Longitudinal Redundancy Check (LRC). 


\section{PENDAHULUAN}

\subsection{Latar Belakang}

Efektivitas Pembelajaran Daring Terintegrasi Di Era Pendidikan 4.0 (Oktavian et al., 2020). Revolusi Industri 4.0 merupakan suatu era terjadinya perubahan di berbagai bidang lewat perpaduan teknologi secara besar-besaran (Oktavian et al., 2020). Dari berbagai vaktor yang terjadi di saat pelaksanaan perkuliahan daring (online) masih terdapat kendala atau eror pada saat perkuliahan daring berlangsung salah satunya visualisasi yang tidak baik, hal ini terjadi di karekan pengiriman dan penerimaan data pada transmiter perangkat mengalami kesalahan atau tidak benar, pada kasus ini akan mengakibatkan delay atau jedah dari visualisasi yang di tampilkan. Untuk mengoptimalkan proses tersebut maka perlu dilakukan pengecekan atau deteksi kesalahan apa yang sedang di alami oleh perangkat pengguna.

Pada penelitian ini penulis menggunakan metode Longitudinal Redundancy Check (LRC), sebagai metode deteksi kesalahan pada proses perkuliahan daring (online) yang mana analisa dari metode LRC ini dapat memberikan hasil analisis sistem, dengan transfer data yang di lakukan secara per blok. Didalam blok terdiri dari 8 byte dan setiap blok memiliki karakter pemeriksa blok yang ditempatkan pada akhir blok dengan metode sederhana sistem interaktif operator memasukan data melalui terminal juga mengirimkan ke komputer sehingga menampilkan kembali ke terminal, agar dapat memeriksa apakah data yang dikirimkan telah benar.

\subsection{Teori Pendukung}

Berdasasrkan hasil penelitian oleh (Rivalri Kristianto, 2013) "Perancangan Perangkat Lunak Diteksi Bit Eror pada Transmisi Data", peneliti juga menerapkan metode Longitudinal Redundancy Check (LRC) dengan menerapkan penambahan parity bit pada data, sebagai metode yang tepat dan dianggap mampu mendeteksi bit eror pada sektor pengiriman data.

Menurut (Adam Mukharil Bachktiar, 2010) "Diteksi dan Koreksi Kesalahan ketika melakukan Pentransmisian Data”. Seringkali dijumpai ketidak sesuaian yang diharapkan, hal tersebut disebabkan oleh gangguan saluran transmisi, pada kasus ini peneliti menggunakan metode vertical redundancy checking (VRC) sebagai metode penditeksi kesalahan tersebut, namun dalam perbaikannya terhadap kelemahan yang ada 
pada metode VRC peneliti menggunakan metode Longitudinal Redundancy Check (LRC), pada metode LCR dibutuhkan banyak tambahan bit pada setiap data yang dikirim, misalkan untuk mengirim 7 karakter (49 bit), maka diperlukan tambahan bit sebnyak 15 bit, metode LRC tidak banyak digunakan, namun sangat bermanfaat dalam proses penyempurnaan deteksi kesalahan atau eror.

\section{Analsis Sistem Informasi}

Analisis sistem merupakan suatu tahapan proses penelitian terhadap sistem yang sedang berjalan yang bertujuan untuk mengetahui segala permasalahan yang terjadi untuk memudahkan proses tahapan selanjutnya, analisis sitem biasa dilakukan sebelum melakukan diteksi terhadap suatu pokok atau inti permasalahan sehingga dapat menentukan titik permasalahan dan melakukan diteksi guna menyempurnakan kinerja sistem yang berjalan.

\section{Visual}

Media pembelajaran audio visual adalah media perantara yang penyerapannya melalui pandangan dan pendengaran sehingga membangun kondisi yang dapat membuat siswa mampu memperoleh pengetahuan, keterampilan, atau sikap yang dipergunakan untuk membantu tercapainya tujuan belajar (Hayati et al., 2017). Visual berhubungan erat dengan indra penglihatan, sebagian ahli mengatakan visual merupakan konteks dari proses belajar yang di mana aktivitas belajar itu sendiri terdiri atas somatis (bergerak dan berbuat) auditori (berbicara dan mendengar) visual (melihat, mengamati dan menggambarkan). rangkaian proses penyampaian informasi atau pesan kepada pihak lain dengan penggunaan media penggambaran yang hanya terbaca oleh indra penglihatan adalah proses dari visual.

\section{Pekuliahan Daring}

Perkuliahan daring merupakan dimana suatu proses belajar mengajar dilakukan dengan bantuan perangkat komputer yang tentunya terhubung dengan jaringan internet, proses ini menampilkan berbagai bentuk visualisasi seperti video, suara dan gambar. Penggunaan pembelajaran daring akan menjadi sangat efektif jika memenuhi komponen esensial dalam pembelajaran yaitu diskursif, adaptif, interaktif dan reflektif dengan 
elemen-elemen yang akan sangat baik jika diintegrasikan dengan lingkungan pembelajar sehingga dapat menjadi pembelajaran daring yang terintegrasi dengan lingkungan atau memenuhi komponen digital learning ecosystem karena dapat mengakomodasi gaya belajar, fleksibilitas dan pengalaman belajar peserta didik sehingga dapat memunculkan perasaan positif (Oktavian et al., 2020).

\section{OSI (Open System Intercobection)}

(Riyadi, 2019) "Open System Interconnection atau biasa disingkat OSI adalah sebuah model referensi dalam bentuk kerangka konseptual yang mendefinisikan standar koneksi untuk sebuah komputer". Tujuan dibuatnya model referensi OSI ini adalah agar menjadi rujukan untuk para vendor dan developer sehingga produk atau software yang mereka buat dapat bersifat interporate, yang berarti dapat bekerja sama dengan sistem atau produk lainnya tanpa harus melakukan upaya khusus dari si pengguna.

\section{UML (Unified Modelling Language)}

Dalam Perancangan Sistem menggunakan pemodelan proses untuk mengilustrasikan aktivitas aktivitas yang dilakukan dan bagaimana data berpindah diantara aktivitas-aktivitas tersebut. Cara untuk merepresentasikan proses model dengan menggunakan UML (Unified Modeling Language). UML merupakan sistem arsitektur yang bekerja dengan Object Oriented Arcitechture Design (OOAD) dengan satu bahasa yang konsisten untuk menentukan, visualisasi, mengkontruksi, dan mendokumentasikan artifact yang terdapat dalam sistem software (Risky Soelaeman, 2019).

Just as building architects create blueprints to be used by a construction company, software architects create UML diagrams to help software developers build the software. If you understand the vocabulary of UML (the diagrams' pictorial elements and their meanings), you can much more easily understand and specify a system and explain the design of that system to others (Pressman, 2010).

\subsection{Rumusan Masalah}

Bagaimana cara memperoleh informasi kesalahan data atau error visual pada sistem perkuliahan daring (online) yang sedang beroperasi dan bagaiman 
mengimplementasikan analisa sistem informasi diteksi kesalahan sistem atau eror visual menjadi rancangan perangkat lunak diteksi bit eror dengan menggunakan metode Longitudinal Redundancy Check (LRC).

\subsection{Tujuan Penelitian}

Adapun tujuan dari penelitian ini adalah guna memudahkan dalam menditeksi kesalahan atau eror sistem yang terjadi dalam proses perkuliahan daring (online), serta agar dapat mengimplementasikan rancangan perangkat lunak dalam menditeksi kesalahan atau eror sistem visual dalam proses perkuliahan daring (online).

\section{METODE PENELITIAN}

Model dan metode penelitian yang digunakan peneliti dalam penelitian ini adalah model referensi OSI yang merupakan model arsitektur yang dikembangkan oleh International Organization for Standardization untuk Standardisasi (ISO) di Eropa pada tahun 1977. OSI adalah singkatan dari “Open System Interconnection” (Riyadi, 2019), dan metode LRC (Longitudinal Redundancy Check), yang merupakan perbaikan dari metode VRC (Vertical Redundancy Check). Serta metode UML yang digunakan untuk memvisualisasi, menspesifikasi dan mengimplementasikan ke sebuah perangkat lunak.

\section{A. Proses Analisa}

\section{Analisa Penerimaan Data}

Biasa penerimaan data merupakan bagian dari telekomunikasi yang secara khusus berkaitan dengan transmisi dan informasi diantara komputer komputer dan alat komunikasi lain dalam bentuk digital yang dikirim melalui media komunikasi data. Data berarti informasi yang telah di ubah kebentuk digital. Data data yang diterima dapat berupa pengirim (sender) adalah piranti yang mengirirn data, penerima (receiver) adalah piranti yang menerima data, Data adalah informasi yang akan dipindahkan, Media pengiriman atau penghantar adalah media atau saluran yang digunakan untuk mengirim data, Protokol adalah aturan aturan yang berfungsi untuk menyelaraskan hubungan berkomunikasi. 


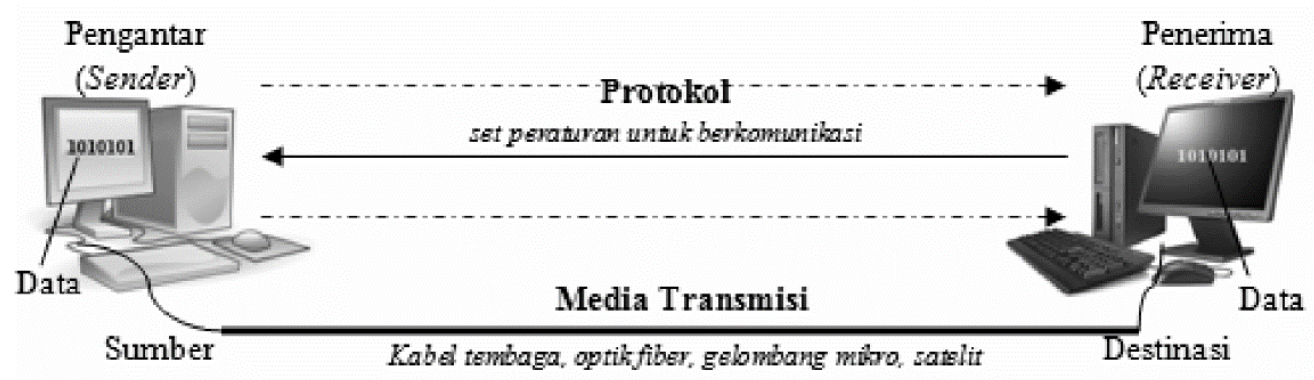

Gambar 1: Komunikasi Data

\section{Analisa Diteksi Bit Eror}

Analisa bit error pada hakikatnya menggunakan metode diteksi bit error, dalam penilitan ini dapat di contohkan proses analisa bit eror. kita akan mengirimkan data 4 bit 1001 dengan sederhana dengan bit paritas berikut di sebelah kanan, dan dengan " melambangkan sebuah gerbang XOR:

\section{Paritas Genap (Even Parity)}

Melalui transmisian data benar (true) :

A ingin mengirimkan: 1001 A menghitung nilai bit parity: $\mathrm{I}^{\wedge} 0^{\wedge} 0^{\wedge} 1=0$

A menambahkan bit paritas dan mengirimkan: 10010

$\mathrm{B}$ menerima: $10010 \mathrm{~B}$ menghitung paritas: $1^{\wedge} 0^{\wedge} 0^{\wedge} 1^{\wedge} 0=0$

B laporan transmisi yang benar setelah mengamati basil genap.

Melalui transmisi data salah (false):

A ingin mengirimkan: 1001

A menghitung nilai bit parity: $1^{\wedge} 0^{\wedge} 0^{\wedge} 1=0$

A menambahkan bit paritas dan mengirimkan: 10010 (TRANSMSI ERROR)

B menerima: $11010 \mathrm{~B}$ menghitung keseluruhan parity: $1^{\wedge} 1^{\wedge} 0^{\wedge} 1^{\wedge} 0=\mathrm{I}$

B transmisi laporan yang tidak benar setelah mengamati basil ganjil yang tak terduga.

B paritas dihitung nilai (1) tidak cocok dengan bit paritas (0) nilai yang diterima, menunjukkan kesalahan bit.

\section{Paritas Ganjil (Odd Parity)}

Melalui transmisian data benar (true) :

A ingin mengirimkan: 1001

A menghitung nilai bit paritas: $\sim\left(1^{\wedge} 0^{\wedge} 0^{\wedge} 1\right)=1$ 
A menambahkan bit paritas dan mengirimkan: 10011

B menerima: $10011 \mathrm{~B}$ menghitung keseluruhan parity:l"0A0^I"I=1

B laporan transmisi benar setelah mengamati basil ganjil.

Melalui transmisi data salah (false):

A ingin mengirimkan: 1001

A menghitung nilai bit parity: $\sim\left(1^{\wedge} 0^{\wedge} 0^{\wedge} 1\right)=1$

A menambahkan bit paritas dan mengirimkan: 10011 (TRANSMISI ERROR)

B menerima: 11011

B menghitung keseluruhan parity: $1^{\wedge} 1^{\wedge} 0^{\wedge} 1^{\wedge} 1=0$

$\mathrm{B}$ transmisi laporan yang tidak benar setelah mengamati hasil ganjil yang tak terduga.

B parisitas dihitung nilai (0) tidak cocok dengan bit paritas (1) nilai yang diterima, menunjukkan kesalahan bit.

\section{Analisa Longitudinal Redudancy Check (LRC)}

Tekhnik LRC sering kali di kaitkan dengan pengembangan tekhnik parity check. Pada LRC, data (payload) atau data yang hendak ditransmisikan disusun menjadi sejumlah baris yang ditentukan (block), kemudian dilakukan perhitungan bit paritas untuk setiap basis dan setiap kolom. Bit paritas baris ditaruh di unjung kanan, sedang bit paritas kolom diletakkan di bagian bawah. Sedangkan urutan transmisi dimulai dari kolom paling kiri kearah bawah.

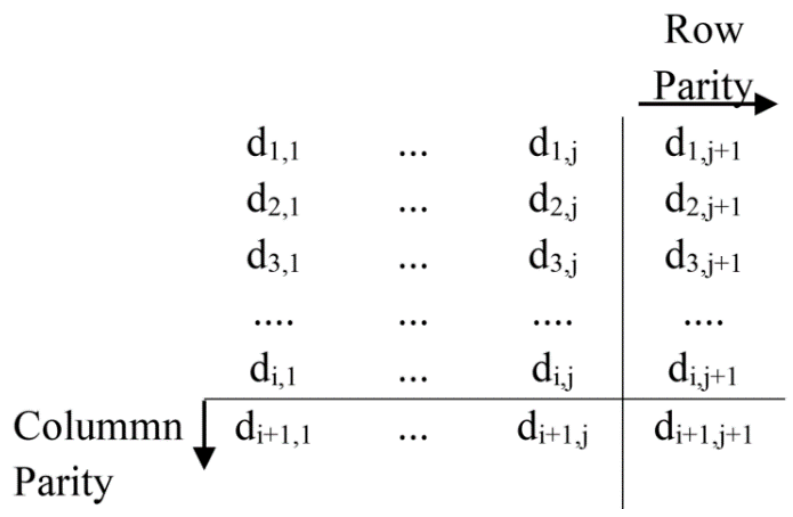

Gambar 2: Longitudinal Redundancy Check 
Dalam melakukan perhitungan LRC, ditambahkan karakter tambahan (bukan satu bit) di bagian kiri dan bagian bawah blok :

1. Block Check Character (BCC) pada tiap blok data. Tiap bit BCC merupakan pariti dari semua bit dari blok yang mempunyai nomor bit yang sama. Jadi bit 1 dan BCC merupakan parity genap dari semua bit 1 karakter yang ada pada blok tersebut, dan seterusnya.

2. Ditentukan seperti parity, tetapi menghitung secara longitudinal pada pesan (dan juga secara vertikal).

3. Kalkulasi berdasarkan pada bit ke-1, ke-2 dst (dari semua karakter) pada blok menggunakan operator XOR (paritas genap) atau - XOR (paritas ganjil).

4. Bit ke-1 dari BCC B jumlah 1 pada bit ke-1 dari karakter

5. Bit ke-2 dari BCC 13 jumlah I pada bit ke-2 dari karakter

a. $98 \%$ laju deteksi error untuk burst errors ( $>10$ bit)

b. Mampu mengoreksi error sebuah bit

c. Mampu mengoreksi error sebuah drive yang rusak (dalam RAID)

6. Perbaikan signifikan dibandingkat parity checking.

\section{HASIL DAN PEMBAHASAN}

\section{Open system Interconnection (OSI)}

Model ini sebagai acuan arsitektural utama untuk network yang mendeskripsikan bagaimana data dan informasi network di komunikasikan dari sebuah aplikasi komputer ke aplikasi komputer lain melalui sebuah media transmisi. OSI adalah singkatan dari “Open System Interconnection". Model ini juga disebut model "tujuh lapisan model OSI" (OSI tujuh lapisan model). Ke tujuh lapisan tersebut memiliki fungsi masing masing. Namun pada penilitian ini, peneliti menerangkan proses dari hasil analisis sistem informasi dalam diteksi eror visual perkuliahan daring dengan metode Longitudinal Redudancy Check (LRC) di proses pada lapisan ke 6 (enam) dan 7 (tujuh) padal pemodelan OSI, yaitu

\section{Layer Presentation}

Layer presentation dari model OSI melakukan hanya suatu fungsi tunggal: translasi dari berbagai tipe pada syntax sistem. Sebagai contoh, suatu koneksi antara PC 
dan mainframe membutuhkan konversi dari EBCDIC character-encoding format ke ASCII dan banyak faktor yang perlu dipertimbangkan. Kompresi data (dan enkripsi yang mungkin) ditangani oleh layer ini.

\section{Layer Application}

Layer ini adalah yang paling 'cerdas', gateway berada pada layer ini. Gateway melakukan pekerjaan yang sama seperti sebuah router, Layer Application adalah penghubung utama antara aplikasi yang berjalan pada satu komputer dan resources network yang membutuhkan akses padanya. Layer Application adalah layer dimana user akan beroperasi padanya, protocol seperti FTP, telnet, SMTP, HTTP, POP3 berada pada layer Application.

\section{Implementasi Perancangan Dan Pengujian Algoritma}

Pada proses perancangan Perangkat lunak pendeteksian bit error dengan metode Longitudinal Redudancy Check ada dua kegiatan yang harus dilakukan pertama pada sisi pengirim dan kedua pada sisi penerima. Pada sisi penerima kegiatan meliputi, menginputkan data berupa pesan teks, pemerosesan pesan teks yang dikonversikan ke biner yang masing mana hasil konversi setiap karakternya di urutkan secara vertikal, selanjutnya hasil dari konversi teks ke biner, masing masing bit setiap karakter secara horizontal di XOR kan dan menghasilkan paritas baris dan secara vertikal di XOR kan dan menghasilkan paritas kolom, terakhir pesan dikirim.

Detail dari penjelasan dapat di contohkan dalam pengkodingan algoritma sebagai berikut :

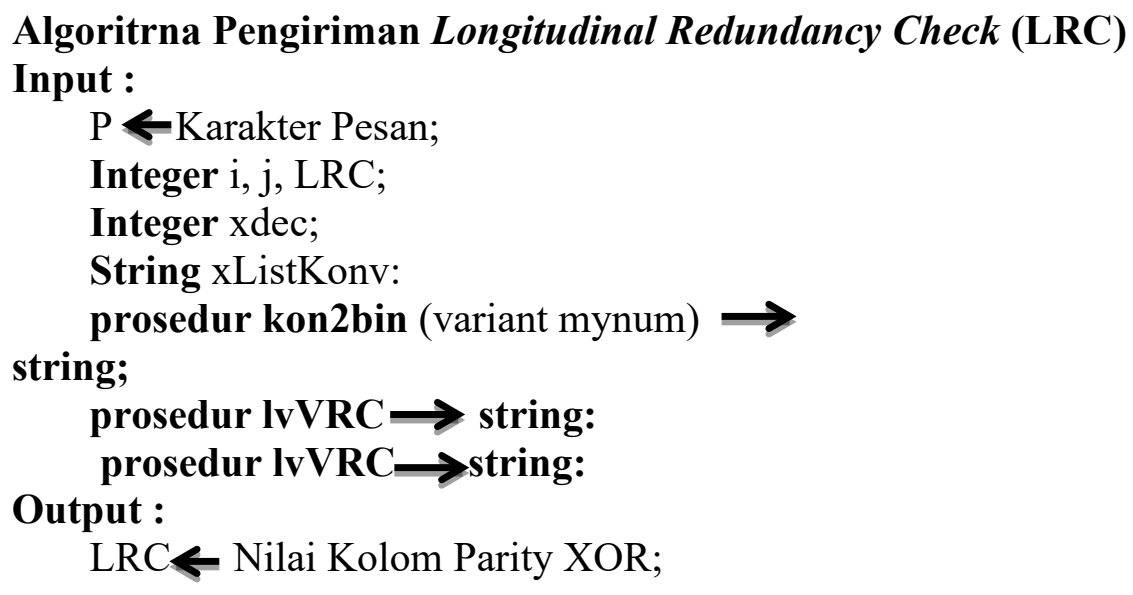




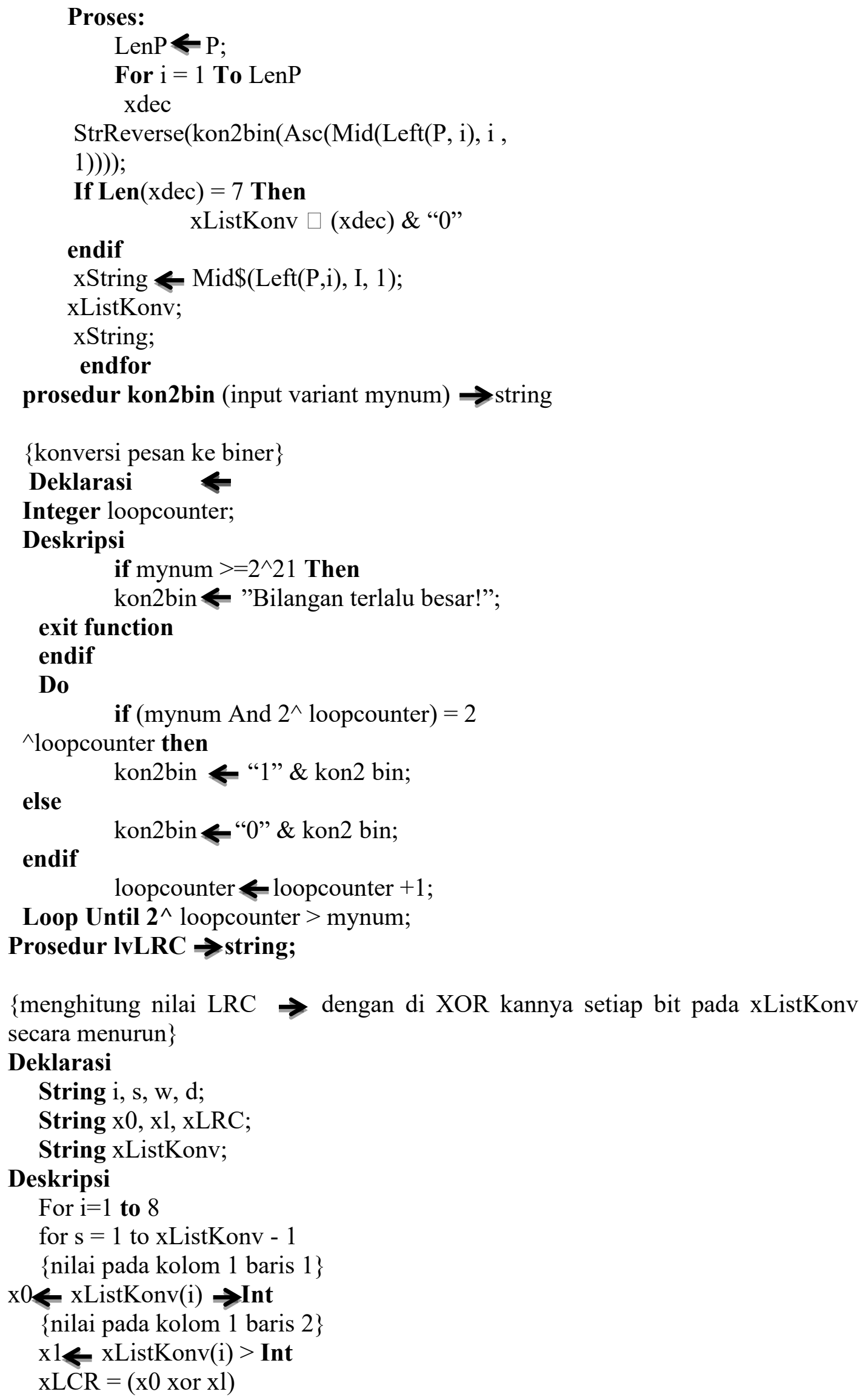

Loop Until $2^{\wedge}$ loopcounter > mynum;

Prosedur IvLRC $\rightarrow$ string;

\{menghitung nilai LRC dengan di XOR kannya setiap bit pada xListKonv secara menurun\}

\section{Deklarasi}

String i, s, w, d;

String $\mathrm{x} 0, \mathrm{xl}, \mathrm{xLRC}$;

String xListKonv;

\section{Deskripsi}

For $\mathrm{i}=1$ to 8

for $\mathrm{s}=1$ to $\mathrm{xListKonv}-1$

\{nilai pada kolom 1 baris 1 \}

$\mathrm{x} 0 \leftarrow \mathrm{xListKonv}(\mathrm{i}) \rightarrow$ Int

\{nilai pada kolom 1 baris 2 \}

$\mathrm{x} 1 \Leftarrow \mathrm{xListKonv}(\mathrm{i})>$ Int

$\mathrm{xLCR}=(\mathrm{x} 0$ xor $\mathrm{xl})$ 


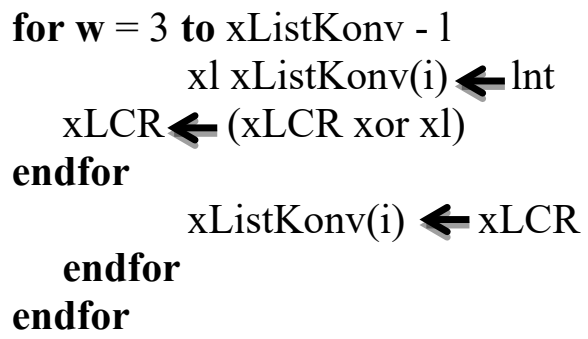

\section{Algoritma Penerimnaan Longitudinrrl Redundancy Check (LRC)}

Didalam algoritma penerimaan pesan akan masuk dengan basil setiap karakter telah di konversikan ke biner dengan di XOR kan setiap bit biner pada masing-masing karakter.

\section{Input:}

\{Pesan Diterima\}

P 4-- Bit Binery Pesan; Integer t, s, w;

String $\mathrm{xO}$, xi

Output:

String xListKonv;

\{basil XOR setiap bit secara menurun maka diketahui nilai

ReceivedLRC) ReceivedLRC t- Nilai Parity XOR keseluruhan Kolom;

Proses:

For $\mathrm{t}=1$ To 8

For $\mathrm{s}=1$ To LV.Listltems.Count -1

\{nilai pada kolom 1 baris 11

$\mathrm{x} 0$ 4- xListKonv(i) $\rightarrow$ Int

\{nilai pada kolom 1 baris $21 \mathrm{xl} 4$ -

$\mathrm{xListKonv}(\mathrm{i})$

$\mathrm{cLCR}=(\mathrm{x} 0$ xor $\mathrm{xi})$

For $\mathrm{w}=3$ To $\mathrm{xListKonv}$

$\mathrm{xl} \leftarrow$ (xListKonv $(\mathrm{w}) . \mathrm{xListKonv}$

$(\mathrm{t})) \rightarrow$ Int

cLCR $\leftarrow$ (cLCR xor xl)

endfor

ReceivedLRC $=$ cLCR

endfor

endfor

\section{Manfaat}

Dengan adanya sistem ini, maka kedepannya akan banyak membantu user/pengguna dalam menganalisa dan menditeksi kesaslahan yang terjadi dalam proses pengoperasian perkuliahan daring, terutama pemasalahan delay/jeda dalam visualisasi. 


\section{SIMPULAN}

Berdasarkan penelitian yang dilakukan, maka dapat disimpulkan, Dengan adanya analisis sistem informasi dalam diteksi error visual maka proses perkuliahan daring (online) kedepannya diharapkan tidak lagi mengalami delay/jeda ataupun kesalahan yang terjadi pada trasmiter data. Inputan proses pada sistem ini dapat juga mendeteksi kesalahan yang terjadi yang dilakukan pada receiver dengan tahapan pengecekan dilakukan dengan menyusun pesan secara horizontal yang dimana hasil konversi biner nya disusun secara blok, dengan masing-rnasing blok memiliki nilai paritas yang di XOR kan secara horizontal dengan menggunakan paritas XOR dan hasil pengiriman pesan yang didapat benar atau salah terletak pada hasil received XOR. Output proses diteksi dari dalam perangkat lunak dengan metode Longitudinal Redundancy Check (LRC) ini memberikan gambaran dengan mendeteksi kesalahan pada saat pengiriman frame antara perangkat keras, gambaran kesalahan dapat berupa hasil konversi biner dengan nilai parietas yang tidinya telah di XOR secara harizontal dan di baca oleh penerima (receiver) setiap pesan dikonvert ke biner sebelum sampai kepada penerima (receiver).

\section{DAFTAR PUSTAKA}

Adam Mukharil Bachktiar. (2010). Pengertian Kesalahan. Ditad Komunikasi Data, 115. Retrieved from https://repository.unikom.ac.id/32669/1/BAB V - Deteksi dan Koreksi Error.pdf

Hayati, N., \& Harianto, F. (2017). Hubungan Penggunaan Media Pembelajaran Audio Visual dengan Minat Peserta Didik pada Pembelajaran Pendidikan Agama Islam di SMAN 1 Bangkinang Kota. Al-Hikmah: Jurnal Agama Dan Ilmu Pengetahuan, 14(2), 160-180. doi: 10.25299/al-hikmah:jaip.2017.vol14(2).1027

Oktavian, R., \& Aldya, R. F. (2020). Efektivitas Pembelajaran Daring Terintegrasi di Era Pendidikan 4.0. Didaktis: Jurnal Pendidikan Dan Ilmu Pengetahuan, 20(2), 129-135. doi: 10.30651/didaktis.v20i2.4763

Pressman, R. S. (2010). Software Engineering: A Practitioner's Approach (F. M. Schilling (ed.); SEVENTH ED). New York.

Risky Soelaeman, H. (2019). Identifikasi Sebaran Wilayah Kebun Teh Hitam Ortodoks Berbasis Web Sistem Informasi Geografis. XI(2), 51-64. ERROR DENGAN IMPLEMENTASI LONGITUDINAL REDUNDANCY CHECK ( 
LRC ) PADA TRANSMISI DATA Diterbitkan Oleh : STMIK Budi Darma Medan Diterbitkan Oleh : STMIK Budi Darma Medan. III, 77-83.

Riyadi, H. (2019). Pengertian OSI Layer Beserta Kegunaan dan Cara Kerja OSI Layer. Pengertian OSI Layer Beserta Kegunaan Dan Cara Kerja OSI Layer. Retrieved from https://www.nesabamedia.com/pengertian-osi-layer/ 